\title{
Dos destroços da paisagem: a cidade em dois poetas brasileiros da década de 1960
}

\author{
Fadul Moura \\ Universidade Estadual de Campinas \\ Fundação de Amparo à Pesquisa do Estado de São Paulo
}

\begin{abstract}
Resumo
O presente trabalho é organizado em dois movimentos que ocorrem de modo paralelo: no primeiro, procura-se a analisar a cidade em dois poetas brasileiros, Luiz Bacellar e Francisco Alvim, pelo viés da ideia de paisagem, de Collot (2013); em seguida, objetiva-se trazer para discussão o fato de que o modo como eles tratam as paisagens urbanas coloca em evidência o topos da crise (SISCAR, 2010) na poesia dos anos 1960. Desse modo, ocorre não só a recuperação de livros ou nomes que se encontram à margem da crítica e da historiografia literárias, mas que também expõem a diferença na poesia brasileira.
\end{abstract}

Palavras-chave: Poesia brasileira; paisagem; crise; Luiz Bacellar; Francisco Alvim.

\begin{abstract}
This paper is organized into two parallels movements: in the first, the city is analyzed through the Collot's concept of landscape; in the second movement, the aim is to discuss the fact that the way the authors articulate their surroundings puts in display the crisis topos (SISCAR, 2010) in the poetry of the 60 's. Hence, it is possible to recover books or names that are marginalized by literary critic and historiography, and also expose the difference in Brazilian poetry.
\end{abstract}

Keywords: Brazilian poetry; landscape; crisis; Luiz Bacellar; Francisco Alvim.

Recebido em: 19/03/19

Aprovado em: 24/07/19

O presente trabalho tem como proposta analisar dois poemas de autores brasileiros que iniciaram suas publicações na década de 1960. São eles Luiz Bacellar, nascido em Manaus (AM), e Francisco Alvim, em Araxá (MG). De suas obras, foi selecionado o primeiro livro de cada autor: Frauta de barro (2011), publicado pela primeira vez em 1963, e Sol dos cegos (1968), respectivamente. Para além da diferença geográfica e de suas trajetórias biográficas evidentemente distintas, com base nos poemas, procura-se mostrar como a apresentação da paisagem da cidade coloca na ordem do dia a concepção de cidades poéticas com características peculiares, de sorte a explicitar a heterogeneidade da modernidade da poesia no Brasil e o topos da crise que tais poesias apresentam. 
Toma-se a ideia de modernidade segundo Octavio Paz, para quem ela "está condenada à pluralidade: a antiga tradição era sempre a mesma, a moderna é sempre diferente. A primeira postula a unidade entre o passado e o hoje; a segunda, não satisfeita em sublinhar as diferenças entre ambos, afirma que esse passado não é uno, e sim plural" (2013, p. 15). Com isso, desejase também recobrar que a produção do Brasil, com a proximidade temporal dos poetas e com o gigantismo territorial claros, não é uniforme, reforçando estilos individuais que extrapolam conjugações da historiografia literária. A isso se associa a adesão à postura metodológica de Ettore Finazzi-Agrò, que, ao pensar sobre a história literária brasileira, procura

conjecturar uma disposição não taxonômica, em que se cruzam cronologias diferentes, numa conexão não consequencial de fatos e de imagens, de eventos e de representações, de ideias e de práticas dispostos apenas no horizonte da pré-ocupação, isto é, de uma ocupação antecedente por parte de quem olha e interpreta, do historiador que lê o passado e prediz o futuro dentro de um presente em que convivem, em potência, formas temporais diferentes e em que aquilo que domina é apenas o estado virtual do que já foi ou do que vai ser, e de que devemos sempre tomar cuidado (2010, p. 36).

O esclarecimento do crítico italiano permite a apreciação dos poemas de Bacellar e Alvim sem amarrá-los a um fio temporal sistematizador de uma continuidade. Não se trata, aqui, de uma negação da dívida que ambos têm com Carlos Drummond de Andrade, por exemplo, nem da sugestão equivocada de que Alvim retomaria Bacellar, mas da abertura de outro caminho. É necessário colocar em primeiro plano a colaboração que ambos oferecem à poesia brasileira, a julgar que tais características excedem categorias fixas na medida em que a si mesmas contrapõem. O cotejo por um entrelaçamento temático reflete um esforço de alinhá-los sem realizar uma leitura causal da produção brasileira, para, assim, sinalizar no presente de uma época as incongruências que lhe são próprias. Associando o pensamento de Finazzi-Agrò ao que propõe Octavio Paz, intenta-se desdobrar a possibilidade de pensar passados concomitantes na poesia brasileira, em virtude das particularidades que expõem.

Nesse sentido, a leitura de cada poema tenciona as marcas do tempo histórico impresso em cada texto e explicita o gesto poético de ler e apresentar parte do que se considera realidade. Isso significa que a poesia está menos afastada do mundo e mais alinhada a reflexões que o atravessam. Para tanto, a hipótese levantada é de que há uma conexão possível pelo olhar que os poetas lançam sobre as cidades em seus livros. Marcadas pela diferença, tais cidades são paisagens que jogam com a matéria do tempo e apontam para momentos distintos. Os observadores dos espaços urbanos estão no presente; porém, enquanto Bacellar orienta a visão do eu lírico para o passado, na abertura de uma crise gerada pelos choques com a memória, Alvim assume o presente como alvo de sua observação, fixando o eu lírico em outro dinamismo, o do que lhe é contemporâneo. A diferença, portanto, está na maneira como lidam com o tempo. E essa é construída não apenas pelas imagens selecionadas para compor o espaço (os prédios e 
a rua, no primeiro; os ônibus e os anúncios, no outro), mas também pela própria estruturação do verso como reflexo da matéria subjetiva. Por outro lado, como elo, a paisagem é capaz de exibir as consequências pelas quais passou o Brasil diante de momentos de transformação urbana, assim como as situações que impactaram os sujeitos líricos de cada livro.

Cabe, ainda, outro esclarecimento. A opção pela ideia de paisagem como antecessora da ideia de cidade decorre da proposta do pensamento-paisagem, de Michel Collot, na qual "paisagem e pensamento entram em uma relação de aposição, aberto [o sintagma] a várias interpretações: permite, ao mesmo tempo, sugerir que a paisagem provoca o pensar e que o pensamento se desdobra como paisagem" (2013, p. 12). Tais sugestões mobilizam sentidos em duas direções: se, na primeira, é a paisagem que suscita a ação, a segunda transforma-a em imagem que se projeta como horizonte para o sujeito lírico. Isso significa que não se deve mais imaginar um sujeito meramente condicionado pelo espaço, muito menos o vetor contrário. A relação de aposição descrita por Collot encena o esfumaçamento da posição hierárquica superior que o sujeito exerceria sobre o objeto; consequentemente, desfaz-se a ideia de sujeito centrado que apreenderia o mundo por meio de uma racionalidade iluminadora de objetos dados. Por esse viés, o olhar dos poetas transforma a paisagem da cidade em pensamento, produto do encontro entre os pontos de vistas deles e o mundo. Nesse encontro, há a abertura da consciência do sujeito lírico para o que é de fora, isto é, para esse lugar de onde podem emergir outras formas de pensamento, pautadas agora não mais no sentido de uma análise intelectual, mas de apreensões sinestésicas que apontam para os afetos que os espaços urbanos também suscitam.

Em análise sobre as edições de Frauta de barro, Allison Leão destaca a permanência do popular no conteúdo do livro e menciona que "no bojo desses poemas, nota-se um desdobramento desse acervo [da memória cultural], pois muitas vezes a coleção dos contos populares desencadeia outra forma de coleção - a dos espaços percorridos pelo afeto e pela memória" (2017, p. 27). A relação proposta pelo crítico exibe o afeto como laço entre memória e espaço, o qual ganha maior gravidade na seção intitulada "Três noturnos municipais". Formada por "Noturno do Bairro dos Tócos", "Noturno da Praça da Saudade" e "Noturno da Rampa do Mercado", o poeta elege espaços mediante o ponto de vista de um viajante (KRÜGER, 2011; MOURA, 2018) que apresenta nesse horizonte o amálgama entre afeto e cidade. Observando o mapa da cidade, é notado que, juntos, os textos compõem um desenho triangular do que foi o antigo Centro da cidade de Manaus e o bairro atualmente conhecido sob o nome de Aparecida. Acompanhar as ruas segundo a ordenação dos poemas oferece um trajeto que poderia ser percorrido a pé da periferia antiga até o Mercado Adolpho Lisboa, à margem do rio Negro, sugerindo, desse modo, o caminho pelo qual se desenha um mapa afetivo em Frauta de barro. 
Em “Noturno do Bairro dos Tócos", verifica-se uma etapa dessa jornada, que extrapola o caráter geográfico e alcança a instância do tempo, conforme se vê abaixo:

Há tanta angústia antiga em cada prédio!

Em cada pedra nua e gasta. E agora

em necessário pranto que demora

amargo o verso vem como remédio

pelos sonhos frustrados em cada hora

da ingaia infância. Madurando o tédio

nos becos turvos, porque exige e pede-o

inquieta solidão que assiste e mora

em cada tronco e raiz, calçada e muro:

Chora-Vintém, O-Pau-Não-Cessa. ${ }^{1}$ Impuro

se derrama um palor de lua morta

nas crinas tristes, no anguloso flanco:

memória e angústia fundem-se num branco

cavalo manco numa rua torta

(BACELLAR, 2011, p. 83).

No argumento do poema encetado logo no primeiro verso está concentrada toda ação desenvolvida pelo poeta. O verbo aponta a existência da angústia como algo inquestionável e a adjetivação que ela recebe confirma uma presença que atravessa os tempos, fazendo recair com intensidade o peso do passado sobre o agora. Essa gravidade retira do presente a validade de si mesmo para sobrevalorizar os eventos pretéritos. A marca de localização encontrada no adjunto adverbial determina duas relações: a do eu com o espaço e, excedendo-a, a do eu com o tempo. Na primeira delas, a emoção faz com que o sujeito lírico viaje para fora de si na medida em que se desloca pelo espaço. Na esteira de Collot, "o ser emocionado encontra-se transbordado, tanto por dentro como por fora" (2018, p. 24). Esse transbordamento fica evidente pela associação dos sentidos do advérbio "tanta" e da exclamação, formando um círculo afetivo que o aprisiona no horizonte observado. Esse horizonte espacial atravessa uma camada temporal e transformase em um momento em que o sujeito fica extático diante da cidade. Essa situação leva à paralisação do movimento do corpo e torna-se mais intensa com a sonoridade das consoantes oclusivas, gerando a sensação de um eu lírico também estanque diante do que vê.

Os adjuntos adverbiais dos dois primeiros versos compõem um jogo de oposição feito pelo tamanho dos elementos (prédio versus pedra). Com uma espécie de zoom, o poeta observa panoramicamente a cidade e, em seguida, aproxima o olhar para esquadrinhar os escombros.

\footnotetext{
${ }^{1}$ Nomes de becos.
} 
Em jogo especular (eu-espaço) desencadeado pela adjetivação, as pedras são qualificadas pela nudez, como se estivessem despidas de algo, e por terem sido deterioradas com o uso e/ou com o tempo. Compreendendo que o dístico nudez-deterioração torna indissociáveis eu lírico e cidade, essa correspondência permite pensar a mudança de referencial também em relação ao eu lírico. Diante das pedras, ele possui uma grandeza que não encontra identidade consigo quando o novo referencial são os prédios. Essa incongruência ratifica a projeção eu-espaço, elaborando um jogo de sentidos entre aquele dístico e aduzindo uma mudança de perspectiva, posto que a paisagem também age sobre ele, de sorte que eu lírico se sinta exposto, despido de suas forças.

Na segunda relação, a referida paralisação exige que o leitor também pare e acompanhe uma segunda dinâmica com mais cautela: aquele movimento do olhar, da extensão do eu. Esse não se dá exclusivamente no espaço, embora seja suscitado por ele, mas pelas próprias lembranças. O leitor não terá acesso a elas no primeiro verso. Isso só irá acontecer, de forma obnubilada, no quinto e no sexto verso, quando mencionados os sonhos e a infância. Por essas alusões sem definição precisa, nota-se um eu lírico envelhecido, que busca reconhecer na paisagem urbana as marcas do que ele mesmo já não é e não mais significa. Diante desse impasse, ele sofre uma segunda vez a frustração dos projetos não realizados. Em outra oportunidade, foi possível distinguir a atitude do poeta de Frauta de barro da atitude do flanêur de Baudelaire. Acreditase que essa diferença é cristalizada pela figura do nostálgico já estudada por Marcos Piason Natali (2006), a qual se fixa no objeto de desejo assentado no passado, embora não possa mais acessá-lo; logo, a diferença da poesia de Bacellar em relação ao poeta francês seria reafirmada pela memória. ${ }^{2}$

Fazendo um levantamento dos verbos do poema, na primeira e na segunda estrofe dois deles compõem um campo de associação de ações alongadas. O "pranto" "demora", oferecendo uma extensão da duração do instante, congelado imediatamente em decorrência da "angústia antiga". O "tédio", em gerúndio, vem sendo "madurado", isto é, lentamente recuperado e revivido. Em uma retroalimentação dos afetos, o tempo do poema parece cristalizar o tempo do relógio, evitando o avançar para o futuro que desamarraria o eu lírico e o levaria à morte inevitável. Essa recusa é marcada uma vez mais pela exigência da "solidão", configurada no texto por verbos que indicam residência, morada. É com isso que o texto explicita o motivo da recusa do eu lírico, antevisto desde o início pelo título do poema. O nome do bairro, Tócos, advém do fato de que o atual bairro de Aparecida teve suas árvores cajazeiras cortadas para que as ruas fossem asfaltadas durante o crescimento da cidade. $O$ trabalho, porém, havia coberto apenas parcialmente as raízes, permanecendo expostas as bases dos troncos que não foram arrancados. Por esse motivo, o poema detalha "cada tronco e raiz, calçada e muro", em um golpe de olhar que se estende de uma

\footnotetext{
${ }^{2}$ Cf. MOURA (2018).
} 
horizontalidade para uma verticalidade, conotando o ponto de encontro de duas épocas com base em materiais que se contradizem. Se as árvores remetem à tópica da infância tão cara à poesia brasileira, o asfalto retoma o signo da deterioração, parodiando o valor da modernidade urbana, ao passo que revela na relação poeta-cidade a sensação do Unheimlich freudiano.

Para Paul Ricœur,

[...] o ato de habitar não se estabelece senão pelo ato de construir. Portanto, é a arquitetura que traz à luz a notável composição que formam em conjunto o espaço geométrico e o espaço desdobrado pela condição corpórea. A correlação entre habitar e construir produz-se assim num terceiro espaço (2007, p. 158).

Considerando que o conjunto verbal trouxe à baila a ideia da habitação, as palavras de Ricœur iluminam o poema e esclarecem a dor do eu lírico diante da perda do que por ele foi construído durante a vida. Se nessa arquitetura da cidade agora existem apenas escombros, isso se dá porque eles são a nova forma da vida possível para a condição do próprio corpo do eu lírico. Explica-se: se o corpo é a base para traçar as primeiras orientações e formar as primeiras cartografias do espaço que é habitado pelo homem, nele são inscritas memórias associáveis diretamente aos espaços vividos; logo, ele se torna eixo entre interior e exterior. Nesta etapa da viagem, o caminhar do poeta pelos prédios desperta o desejo pelo reconhecimento que não se realiza, pela anagnórisis que não se completa. Destarte, ele não encontra correlação entre espaço habitado e espaço vivido, muito menos aquele terceiro espaço da memória. A familiaridade é ofuscada pela sensação de estranheza que a cidade nele acarreta. Roberto Vecchi, em sua análise sobre o espaço, aponta no estudo etimológico de Carl Schimmit uma particularidade. A palavra latina spatium é formada por $s$, que desempenha função separadora incisiva (ex.: separare, se-care, se-lecio), ligada a patium, que carrega o sentido de patere, "ser aberto". Isso significa, para o crítico, que "o termo espaço remeteria para o sentido de encaixe, de corte, de recorte. Portanto, não se trataria do aberto, mas, linguisticamente, da sua privação - que não é o seu contrário, mas uma dimensão parcial, cerrada e inabitável. Um intervalo, em suma" (VECCHI, 2009, p. 168). Com essa recuperação, Vecchi traz uma nova ideia para a observação do verso que sublinha a composição das matérias distintas. A alteração que sofreu o espaço da cidade pela ação da modernidade coloca em cena o sentido de spatium enquanto a separação que provoca uma fissura no poeta. Cindido, resta-lhe procurar por uma forma de religar-se. É por esse caminho que o "amargo o verso vem como remédio". A palavra poética é aquela que seria capaz de estabelecer uma dialética entre os tempos, permitindo, como um pharmakon (RICEUR, 2007), a reconstrução das lembranças que atenuariam as emoções tão graves que o eu lírico em si carrega.

Não é gratuita, nesse sentido, a imagem final de um "cavalo manco" em uma "rua torta". Com o enjambement na última estrofe, o verso pode ser lido como uma síntese imagética das 
frustrações do eu lírico. Elencando uma imagem arcaica e enfraquecida, combinada à paisagem como reflexo de si, Bacellar demarca a posição de quem testemunha a transformação da cidade e luta para manter-se inalterado. É evidente que essa inalterabilidade não passa de ânsia irresoluta; porém, é por meio dessa imagem que é exposto o duelo entre memória e esquecimento.

A luta travada entre memória e esquecimento nas figuras selecionadas por Luiz Bacellar afasta-se da proposta encontrada em Sol dos cegos, de Francisco Alvim. Diferentemente do primeiro, Alvim não escolhe para assunto de sua poesia uma cidade com o mesmo processo de transformação. Por conseguinte, não será mais o caso de enfrentar a matéria do tempo com a atitude incessante de quem procura conservar sua memória. No aspecto formal, a opção de Bacellar pela forma fixa do soneto é correlata à proposta de conservação do conteúdo e à gravidade do noturno - forma musical preparada para expressão de tons de melancolia ao ser tocada a piano. Isso não acontece nos versos de Alvim. A opção por outra forma de poesia alinha-se ao conteúdo de uma cidade que já ultrapassou essa etapa de urbanização, o que retrata outro momento do passado brasileiro. Ao comentar a virada da poesia de Alvim em relação à de Drummond, José Guilherme Merquior declara:

O novo princípio da solidão em Alvim substitui o senso da anterioridade do ego (indissociável no plano simbólico, da transição sociedade brasileira tradicional / sociedade moderna, vivida e interpretada pelos modernistas) por uma consciência agônica da vulnerabilidade do indivíduo em face da "paisagem humana", do meio social, do comércio doloroso e imediato com o nosso presente social, com o tempo agressivo do ethos urbano moderno (1972, p. 198-199).

Se Bacellar estava mais apegado ao plano simbólico da transição — o que não o alinha à proposta do modernismo paulista por razões que seu texto expõe —, Alvim será aquele que apresentará em seus versos um dinamismo muitas vezes agressivo da cidade. Devido a esse dinamismo, não é possível determinar um mapa das ruas percorridas, muito menos um delineamento capaz de compor afetivamente pontos sobre os quais seriam erguidas memórias. O imediatismo da vida cotidiana é percebido por Alvim e expresso em seus versos desde o princípio pela ausência da forma fixa. Essa mutabilidade da paisagem urbana recairá e alterará constantemente o que Merquior declara como paisagem humana, em decorrência de não haver mais um único personagem a transitar pela cidade, mas vários. A ideia da grande cidade é exposta pela numerosidade de imagens que são lançadas como flashes, a atualizar constantemente a ação em curso interminável. Desse modo, o presente é tomado pela fugacidade; todavia, paradoxalmente ela não o esgota.

"Corpo" é o poema que se encontra na primeira parte do livro de Alvim, sendo anterior a "Paralaxe". Essa localização chama a atenção do leitor porque o poema poderá ser lido 
como uma preparação para o crescendo desenhado no conjunto dos textos. Ainda segundo Merquior, o corpo na poesia de Alvim deve ser tomado como "sensorium da dialética entre a consciência individual e essa realidade" (1972, p. 199). Dizendo de outro modo: ele terá seu sentido ampliado, para deixar de ser aquilo que contém a consciência lírica e se tornar lugar de passagem, isto é, lugar onde a dialética entre as instâncias se faz possível. Compreende-se uma aproximação entre o sensorium de que fala Merquior e a ek-sistência pensada por Collot. Segundo o crítico francês, "a ek-sistência é o movimento pelo qual a consciência sai de si para ir ao encontro do mundo e lhe dar um sentido. Esta significação é elaborada na experiência sensível de si mesma, que é, ao mesmo tempo, um acesso às coisas e uma expressão de si” (2018, p. 35). Nesse acesso, novamente é marcada uma abertura, uma passagem pela qual será feito o câmbio entre campos que a priori seriam considerados separados. Com a dilatação do sentido da palavra corpo anunciada no título, a produção da paisagem considerará o fato de que ela não será mais um recorte do horizonte panorâmico, mas um organismo. Alvim procura expressar a cidade pela forma orgânica com que ela se realiza no plano da vida; logo, identificar o corpo do poeta com o lugar de passagem permite a visualização de um sujeito imerso nesse mundo em que o tempo não desacelera, como pode ser visto nos versos abaixo:

\author{
quantas cidades \\ te percorrem passo a passo \\ antes de entrar nos mil lares \\ que te aguardam \\ é mesmo preciso usar sapatos \\ porque não gastar na pedra \\ uma pele que se lixa longe do \\ tato \\ dentro do ônibus os dias \\ viajam sentados \\ em meio a ombros colados \\ túneis esgoto bichos \\ sorvetes coxas anúncios \\ uma criança um adulto \\ modelam a cidade \\ na areia \\ longe \\ perto do coração onde \\ uma cabeça gira o \\ mundo \\ correndo na grama a sombra \\ de quantos assistem sentados \\ enquanto das traves pende \\ o corpo de um de todos \\ enforcado
}




\begin{abstract}
enquanto as orelhas ouvem
ouvem

e não gritam

há um fora dentro da gente

e fora da gente um dentro

demonstrativos pronomes

o tempo o mundo as pessoas

o olho
\end{abstract}

(ALVIM, 1968, p. 45-46).

O poema oferece um percurso que excede o convencional. A relação do poeta com a cidade acontece no momento em que ela também o atravessa - com o destaque conferido ao plural nos dois primeiros versos. Essa mudança de perspectiva impede que o poema seja lido com absoluta progressão imagética, uma vez que não há mais um único ponto de observação. Ao ver a cidade de dentro, o poeta recusa a funcionalidade e o encadeamento teleológico para observar fragmentos de ideias nos conjuntos dos versos. Do primeiro ao quarto verso, por exemplo, poderia ser seccionado um grupo de imagens que não se associam em uma narrativa sequencial com os versos posteriores, de sorte a evitar um agrupamento sintático construído pelo efeito da pontuação - que não existe. Seguindo uma inclinação benjaminiana, como mônadas, "cada ideia contém a imagem do mundo. A tarefa imposta à sua representação é nada mais nada menos que a do esboço dessa imagem abreviada do mundo" (BENJAMIN, 2013, p. 36-37). Explica-se: como abreviações, as figuras de acesso à cidade indicam que ele pode ser feito por mais de um canal aberto à interpretação; logo, a prática da legibilidade sobre tal cidade poderá ser iniciada por mais de um ponto de observação e seguir mais de uma orientação. Cabe ao leitor associar as palavras por analogias que se estabelecem como constelações.

Uma delas seriam os substantivos "cidades" e "dias", os quais estão emparelhados a pessoas em deslocamento por meios diferentes no texto. Enquanto as primeiras estariam a pé, as demais seriam levadas "dentro dos ônibus". Essa aparente ingenuidade sinaliza figuras em atividade e passividade, pautadas em ações cotidianas que sugerem certa circularidade, posto que a lógica da locomoção no plano do tempo presente postula uma repetição diária. No que diz respeito à ideia do tempo na cidade, Olgária Matos afirma que "o presente da repetição mecânica do mesmo gesto é um presente sem história, é momentâneo, carente da recordação. É o presente produtivista da economia de mercado que domina a Metrópole" (1982, p. 46). Com tais palavras, procura-se iluminar os versos de Alvim, a fim de desenredar a lógica do capital que por meio deles se insinua. Se fosse possível visualizar a cidade do alto, a repetição dos gestos elaboraria uma imagem formada por linhas. Se cada pessoa que por ela atravessasse fosse posta em uma linha de cor diferente, seriam percebidas composições de uma malha humana no espaço citadino. O exame dessa aparência de desorganização corrobora o cruzamento de vidas em ruas intencionalmente e ao acaso, além da própria ideia da cidade como organismo vivo e mutável. 
Salientam-se das palavras de Olgária Matos a economia e o desalojamento que a cidade incita nas figuras que nela habitam. Por isso, quando temporalizadas em "dias", as pessoas assumem as duas faces da moeda espaço-tempo; porém, ironicamente a faceta de um tempo possível para a memória com o avançar dos dias é extraviada pelo excesso de um presente repetitivo.

Essa estratégia pelo uso de fragmentos retoma a enumeração caótica pensada por Leo Spitzer (1961). ${ }^{3}$ O uso desse estilo com série de enumerações estilisticamente heterogêneas é associado à função metafisicamente conjuntiva, segundo o crítico. A enumeração de coisas desconexas ("túneis esgotos bichos / sorvetes coxas anúncios") revela em Alvim a série de objetos com corporeidade material, conferindo caráter dinâmico aos versos, na medida em que expressa mais a ideia de separação que de unidade. Assim, seus versos possuem uma função disjuntiva em lugar de conjuntiva, o que justificaria o distanciamento das "orelhas" que "ouvem / e não gritam". Apesar do som enlaçar os pedaços do corpo, a cisão formal sugere uma dissociação entre a recepção do som pela audição e o entendimento da mensagem, postulando a desconexão entre os termos e, por consequência, entre as pessoas. Isso se desdobra no campo dos sentidos, sugerindo a interrupção da mensagem por meio do corte da compreensão, o qual acarreta, em segundo plano, a impossibilidade de (re)produção de um discurso que continue o anterior. Ela não poderá ser transformada em discurso pelo impasse irônico que o organismo elabora: em vez de harmonizar de forma concatenada aqueles que nele estão imersos, ele os isola.

Outra porta de acesso sensível à cidade também está nas expressões "usar sapatos" e "não gastar na pedra / uma pele que se lixa longe do / tato". Elas remetem ao sentido do tato que no poema parece ser evitado, de modo que a sensibilidade dos habitantes venha sendo reduzida com a naturalização dos efeitos do capital. Os "sapatos", como uma camada que impede de tocar o solo, deixa o sujeito próximo da realidade vivida, mas impossibilita-o de ter contato imediato com ela. O desgaste sobre o sujeito é anterior à realização da vida, o que exibe, por sua vez, que a cidade opera sobre ele uma deterioração sem que ele perceba sua autodestruição.

Considerando a composição monadológica de Benjamin e a proposta enumerativa de Spitzer, acredita-se que a potência dos fragmentos, levada às últimas consequências pela análise de Roberto Vecchi ${ }^{4}$ e destacada pela de Lu Menezes 5 sobre a poesia de Alvim, encontra seu valor "em mostrar uma determinada realidade, em vez de servirem como elos de raciocínio linear e conclusivo" (OTTE, 2009, p. 215), pois aduzem passagens pela e na cidade. Se for possível repensar com Otte o raciocínio desenvolvido por Benjamin, relacionando-o ao estilo enumerativo, o poema de Alvim será percebido como composição fragmentária de um caos

\footnotetext{
${ }^{3}$ Uma primeira leitura sobre o poema de Alvim e o procedimento estudado por Spitzer foi feita pela professora $\mathrm{Dr}^{\mathrm{a}}$. Viviana Bosi antes mesmo do autor deste texto, em curso ministrado no segundo semestre de 2018 no Programa de Pós-graduação em Teoria da Literatura e Literatura Comparada da USP. Tal leitura está em vias de publicação futura.

${ }^{4} \mathrm{Cf}$. VECCHI (2006).

${ }^{5}$ Cf. MENEZES (2013).
} 
que recusa constantemente a estruturação rígida e ordenada por meio da estrutura disjuntiva de seus versos. O eu lírico já havia anunciado no livro sua ação destrutiva: "Com gula autofágica devoro a tarde" (ALVIM, 1968, p. 40). Essa devoração prenunciada no poema "Uma cidade" serve de pedra de toque para compreender o funcionamento da cidade em "Corpo", que, por seu turno, traz alegoricamente "o corpo de um de todos / enforcado". Com esse compartilhamento do uno pelo múltiplo, o poema lança luz sobre a face mais brutal da cidade que se consome. Combinada às metonímias no texto, ela exprime sujeitos destituídos de totalidade e igualmente entrecortados. A julgar, ainda, que ela pode ser lida como uma mônada, a insensibilidade que vinha sendo desenhada antes alcança maior escala quando os habitantes ignoram a morte. Tratase, assim, do extremo da neutralização da empatia.

A imagem final do texto é elaborada pelo quiasmo "fora dentro da gente" / "fora da gente um dentro". Ele ilustra o cruzamento do dístico interno-externo, indiviso pela ideia de que a cidade habita o homem assim como ele também a habita. Essa dissociação da sensibilidade que se identifica com o que lhe é externo, mas não empático, coloca aqueles que deveriam ter nomes (ou seja, identidade) na condição de acompanhantes dêiticos. Desse modo, os sujeitos são destituídos de sua personalidade na cidade de Alvim para assumirem referenciais também mutáveis. Por fim, o último verso coloca em primeiro plano o poeta: o "olho" no final do poema que com a cidade - seu horizonte - tem um encontro, estático, sem poder alterar o organismo, revela a figura de um poeta observador do mundo vivo diante de si.

Tais livros, por si próprios, não precisariam destas observações para serem reconhecidos como faces diversas da cidade na poesia brasileira da década de 1960. Por meio do esforço aqui empregado, compreende-se que a demarcação das diferenças traz à tona temporalidades distintas não só da poesia brasileira, mas também da história do país. Sabendo que a palavra "emoção" deriva do latim emovere, em que o $e$ - (variante de ex-) significa "fora" e movere significa "movimento", a poesia será o que apresenta o dinamismo da subjetividade que se desloca e, por sua vez, expõe o movimento de uma crise que se dá no encontro com o fora. Entender essa emoção na esteira de Collot (2018) subsidia a compreensão de que ela não é exclusivamente interior, mas que se origina no encontro com que está fora do eu lírico, isto é, ela encontra na paisagem urbana um elo - que aqui não se deseja ler como pacífico - entre os autores.

Assim, a encenação da crise que o poeta percebe em seu tempo é visualizada, em Bacellar, nas árvores cortadas, as quais deixam seu legado morto como uma paisagem natural soterrada pela cidade, mas que ainda aparece na forma de um cadáver. Nesse sentido, ele oferece como impasse uma imagem poética que traduz a emergência de choques desencadeados pela dissidência dos tempos. Por outro caminho, tem-se nos versos finais de Alvim a dinâmica da pluralidade das ações fixadas em um presente, sem promover um encadeamento harmonioso, mas um isolamento testemunhado pelos olhos de um poeta atônito diante da cidade. Assim, a 
relação espacial que os sujeitos poéticos estabelecem com a cidade em seus poemas dramatiza o tempo de modo diverso. A geografia passa a ser fundamento da construção da memória, de um lado, mas sua indeterminação impede que o poeta se fixe em qualquer ponto, por outro. Retomando Michel Collot:

O ambiente visual do homem não é uma audição de estímulos pontuais, mas um conjunto estruturado pelo ponto de vista do observador, que põe as coisas em relação umas com as outras, segundo um processo complexo de "ocultação reversível”. Isso acontece porque nossa visão jamais nos dá a ver tudo ao mesmo tempo; ela não obtém um panorama, mas um agrupamento de perspectivas parciais, que se modificam e se completam à medida que nosso ponto de vista se desloca. Nosso campo visual é delimitado por uma borda (edge) que separa o que nos é mostrado do que ainda não o foi ou do que não o é mais, mas esse limite é móvel e reversível e, quando um aspecto é ocultado, não passa a ser menos integrado ao que é percebido [...] (2013, p. 21).

Da observação em forma relativamente linear à composição fragmentária são destacados pontos de vista que erigem paisagem urbanas de acordo com a organização (ou esforço de organização) que o poeta elabora. Colocar os escombros da cidade em uma conexão dependente de um passado, em Bacellar, é uma estratégia que evidencia nos prédios em ruína uma possibilidade de construção com base nos restos. Deles nasce uma narrativa estruturadora de um constructo mnemônico capaz trazer à tona a história do eu lírico e da cidade. Por outro lado, a forma de composição de Alvim retoma a impossibilidade da visão totalizadora. É evidente na escritura do poema uma tentativa de ilustrar ironicamente tal conjunto estruturado e pautado na fragmentação. A parcialidade é o que sobressai pelo próprio corte dos sintagmas e dos versos, uma vez que ela remete às perspectivas plurais que extrapolam um olho centralizador do mundo. A borda em ambos os casos é o lugar de acesso pelo qual se experimenta a mobilidade dos limites. Logo, é necessário levar em consideração que ambas as formas de paisagem apresentam cidades em que não se pode mais estar como um espaço passível de uma convivência apaziguada, mas de separação ou estilhaçamentos. As passagens que os poetas executam, isto é, os caminhos trilhados pela paisagem urbana, denotam momentos que trazem à tona a percepção da transformação; logo, põem na ordem do dia um momento de crise. Com o deslocamento dessa crise no espaço também para o tempo, o poeta posiciona-se frente à história. Se for possível ler essa crise como um topos que se mostra nessas paisagens, tais poetas serão produtores de discursos ativos e críticos. Para Marcos Siscar, em sua leitura sobre a crise na poesia moderna, “[...] [o] discurso poético é aquele que não apenas sente o impacto dessa crise, não apenas deixa ler em seu corpo as marcas da violência característica da época, mas que, a partir dessas marcas, nomeia a crise - a indica, a dramatiza como sentido do contemporâneo" (2010, p. 10). Dizendo de outro modo: a poesia demonstra a sensibilidade do poeta em perceber a crise e evidencia o ato de escrever como modo de inscrição das tensões no campo da palavra. 
Cruzando emoção e tensão, as imagens da paisagem urbana serão produtos de um discurso que sinaliza o que está em crise no momento contemporâneo de cada autor. Embora isso pareça contraditório em Bacellar, devido ao seu olhar para o passado, é prudente lembrar que os verbos estão no presente, portanto, o leitor está diante de um poeta mais alinhado à nostalgia como olhar crítico e menos à contemplação ingênua do pretérito. Caso mais evidente é o de Alvim, que, com a perspectiva voltada ao agora, problematiza os vários pontos de vista e a recusa à determinação específica que a cidade impõe. Desdobrando as palavras de Siscar para os textos em xeque, a nomeação seria feita na poesia por meio de imagens, isto é, por um gesto que desvia da norma para dizer-se de outro modo. Isso traduz um esforço que no poema se percebe para explicitar, pelo encadeamento que nele se instala, a forma da crise. Aqui, arrisca-se dizer que, enquanto no primeiro poeta ela poderia ser chamada de paradoxo,${ }^{6}$ no segundo, o nome mais adequado seria fragmentação. A técnica, nesse sentido nomeador, não é distinta do conteúdo, mas aglutinada à matéria textual indivisa e acabada; a crise, então, é uma ação visualizada pelas imagens e pela escritura dos versos. Abstrai-se disso o fato de a poesia brasileira da década de 1960 continuar perfazendo, nesses dois casos, caminhos por imagens e campos semânticos que aludem à crise na poesia moderna.

Segundo Celia Pedrosa, em sua análise sobre as poéticas do olhar na poesia brasileira,

a iluminação plena vai se transformando em intrincada tessitura de luz e sombra, elidem-se subjetividade e objetividade, visibilidade e invisibilidade, problematizando e reorganizando relações espaciais, temporais e com elas a identidade do caminhante (2011, p. 120-121).

As palavras de Pedrosa possibilitam o reconhecimento da posição que os poetas ocupam em seus textos, isto é, o ponto de observação do eu lírico. Eles ilustram — na esteira de Rancière (1995) — um ver que acontece ao passar. ${ }^{7}$ Ao fim, essas problematizações ganham matizes em cada poeta, na medida em que suas visões apresentam o seu modo de ver no horizonte do espaço urbano em crise, porque neles são traduzidos mais que a descrição da paisagem, mas a abertura à palavra poética com a qual escrevem a vida.

\footnotetext{
${ }^{6}$ Isso, porém, não inclina a poesia de Bacellar apenas para uma conciliação amena dos contrários, mas também para a presença dos opostos. Apesar do verso surgir como pharmakon, tem-se nessa ideia a permanência da diferença, a qual não permite que ela seja denegada.

${ }^{7}$ Analisando a palavra de Racière, Pedrosa ainda destaca que "[...] poeta andarilho que passa a percorrer a literatura do Ocidente a partir do pré-romantismo, se expondo ao contato com diferentes espaços, redefinindo-os e também a si mesmo em um movimento constante, ao mesmo tempo de retorno e de transtorno à representação clássica da paisagem, da viagem e do saber e da liberdade por estas possibilitados [...]" (PEDROSA, 2011, p. 121). Entre retorno (ao passado) e transtorno (no presente), compreende-se que os poemas aqui elencados dramatizam a crise com imagens de paisagens que os desdobram sempre para fora, afastando-os da ideia de uma poesia puramente subjetiva. Sobre isso, procura-se escrever de forma mais acabada em outro espaço.
} 


\section{Referências}

ALVIM, Francisco. Sol dos cegos. Rio de Janeiro: Olímpica, 1968.

BACELLAR, Luiz. Frauta de barro. 9. ed. Manaus: Valer, 2011.

BENJAMIN, Walter. Origem do drama trágico alemão. Tradução: João Barrento. 2. ed. Belo Horizonte: Autêntica, 2013.

COLLOT, Michel. Poética e filosofia da paisagem. Coordenação de Tradução: Ida Alves. Rio de Janeiro: Oficina Raquel, 2013. . A matéria-emoção. Tradução: Patricia Souza Silva. Rio de Janeiro: Oficina Raquel, 2018. FINAZZI-AGRÒ, Ettore. O "tempo preocupado" para uma leitura genealógica das figuras literárias. In: MOREIRA, Maria Eunice (Org.). Histórias da literatura: teorias e perspectivas. Porto Alegre: EDIPUCRS, 2010.

KRÜGER, Marcos Frederico. A sensibilidade dos punhais. Manaus: Muiraquitã, 2011.

LEÃO, Allison. Reedição, repetição e diferença em Frauta de barro. In: MOURA, Fadul; SERAFIM, Yasmin; OLIVEIRA, Rita Barbosa de. (Orgs.). Amazônia em perspectiva: cultura, poesia, arte. Rio de Janeiro: Letra Capital, 2017.

MATOS, Olgária Chain Féres. A cidade e o tempo: algumas reflexões sobre a função social das lembranças, Revista Espaço \& Debates, n. 7, p. 45-52, out./dez. 1982.

MENEZES, Lu. Francisco Alvim. Rio de Janeiro: EdUERJ, 2013.

MERQUIOR, José Guilherme. A astúcia da mímese: ensaios sobre lírica. Editora José Olympio: Rio de Janeiro, 1972.

MOURA, Fadul. Espaços de gravidade flutuante: da vertigem em três estações movediças em Frauta de barro, Faces da História, [s.1.], v. 5, n. 2, p. 7-30, dez. 2018. ISSN 2358-3878. Disponível em: http://seer.assis.unesp.br/index.php/facesdahistoria/article/view/1107. Acesso em: 3 jan. 2019.

NATALI, Marcos Piason. A política da nostalgia: um estudo das formas do passado. São Paulo: Nankin, 2006.

OTTE, Georg. Mostrar e dizer: o fragmento em Passagens, de Walter Benjamin. In: SOUZA, Eneida Maria de; MARQUES, Reinaldo (Orgs.). Modernidades alternativas na América Latina. Belo Horizonte: Editora UFMG, 2009.

PAZ, Octavio. Os filhos do barro: do Romantismo à vanguarda. Tradução: Ari Roitman e Paulina Wacht. São Paulo: Cosac Naify, 2013.

PEDROSA, Celia. Poéticas do olhar na contemporaneidade. In: . Ensaios sobre poesia e contemporaneidade. Niterói: Editora da UFF, 2011.

RANCIÈRE, Jacques. Politicas da escrita. São Paulo: Editora 34, 1995.

RICEUR, Paul. A história, a memória, o esquecimento. Tradução: Alain François. Campinas: Editora Unicamp, 2007. 
SISCAR, Marcos. Poesia e crise: ensaios sobre a "crise da poesia" como topos da modernidade. Campinas: Editora Unicamp, 2010.

SPITZER, Leo. Linguística e história literária. 2. ed. Madrid: Gredos, 1961.

VECCHI, Roberto. Do histórico no fragmento do pós-trágico: quando o poema leva a sério a piada. In: FINAZZI-AGRÒ, Ettore; VECCHI, Roberto; AMOROSO, Maria Betânia. Travessias do pós-trágico: os dilemas de uma leitura do Brasil. São Paulo: Unimarco, 2006.

. Postscriptum: o espaço no tempo do abandono. In: RAVETTI, Graciela; CURY, Maria Zilda; ÁVILLA, Myrian (Orgs.). Topografias da cultura: representação, espaço e memória. Belo Horizonte: Editora UFMG, 2009.

\section{Minicurrículo}

Fabio Fadul Moura é mestre em Letras e Artes pela Universidade do Estado do Amazonas (2016). Atualmente é doutorando do Programa de Pós-graduação em Teoria e História Literária da Universidade Estadual de Campinas (UNICAMP) com bolsa concedida pela Fundação de Amparo à Pesquisa do Estado de São Paulo (FAPESP).Atua ocmo pesquisador do Grupo de Estudos e Pesquisas em Literaturas de Língua Portuguesa (GEPELIP) e do Grupo de Estudos Relações de Gênero, Poder e Violência nas Literaturas de Língua Portuguesa (ambos na UFAM). Além disso, é pesquisador do grupo Investigações sobre Memória Cultural em Artes e Literatura (MemoCult), da UEA. 